\title{
Change of individual BMI in Switzerland and the USA: \\ a multilevel model for growth
}

\author{
OLIVER LIPPS ${ }^{*}$ \\ FLORENCE MOREAU-GRUET $^{* *}$
}

\begin{abstract}
Objective The aim is to analyze and compare individual BMI growth patterns of adults from Switzerland and the U.S.

10 Methods The analyses are based on data from two population representative longitudinal household surveys, one from Switzerland, the other from the U.S. Each data set contains up to four data points for each adult individual. We use multilevel models for growth.

Results It can be shown that growth patterns are different in different cohorts in the two countries: there are only small growth differences in the youngest and oldest, but large

15 differences in the middle ages. The individual BMI increase of the middle age Swiss amounts to only half of that in the comparable U.S. individuals.

Conclusion Given the much higher BMI level especially in the youngest cohort, this points to severe obesity problems in the U.S. middle aged population in the near future. A positive correlation between individual BMI level and growth may aggravate this fact.
\end{abstract}

Keywords: individual BMI, multilevel model for growth, USA, Switzerland

\footnotetext{
* Corresponding author: Swiss Foundation for Research in Social Sciences (FORS), c/o University of Lausanne, CH - 1015 Lausanne, oliver.lipps@fors.unil.ch.

** Swiss Health Observatory, CH - 2010 Neuchâtel.
} 


\section{Introduction}

The prevalence of overweight and obesity in adults has sizably increased over the last years in many developed countries. Commonly the Body Mass Index (BMI) that is obtained

5 by dividing a person's weight in kilograms by the square of height in meters is used. Overweight is defined as a BMI higher than 25 but less than 30, and obesity as a BMI higher than 30. These definitions are based on evidence that health risks increase more steeply in individuals with a BMI higher than 25.

In Switzerland many studies confirm this increase. In the Swiss Health Study (Statsanté 2007), the global prevalence rates of overweight in adults were $25.9 \%$ in $1992,28.5 \%$ in 1997, and $29.4 \%$ in 2002. The corresponding prevalence rates of obesity amounted to 5.6\%, $7.0 \%$ and $7.7 \%$, respectively. Based on the Nutri-Trend-Study from 2000, $26 \%$ of the participants were overweight, and 5\% were obese (Eichholzer and Camenzind 2003).

As for the development over time, the Bus Santé that is based on a random sample of

15 residents of Geneva, showed that overweight or obesity prevalence rates increased by $10 \%$ points in men and 8\% points in women between 1993 and 2000 (Galobardes et al. 2003). A non-representative study (Groscurth et al. 2003) of a Swiss Life insurance company examined 20-39 aged applicants during the time period 1950-1990. The absolute body weight increased continuously, with the most pronounced increase occurring in individuals aged 20-29 above the 90th percentile of body weight and BMI. That means already overweight and/or obese individuals showed the largest increase.

The occurrence of overweight and obesity is even higher in the U.S.. Results from the 2003-2004 National Health and Nutrition Examination Survey (NHANES) indicate that 66\% of U.S. adults are either overweight or obese (Ogden et al. 2006). Concerning time effects, data from two NHANES surveys show that among adults aged 20-74 years the prevalence of 
obesity increased from 15\% in 1976-1980 to 33\% in 2003-2004 (Flegal et al. 2002; Kuczmarski et al. 1997).

Most studies collect data on height and weight based on self reports. Comparing two 5 Swiss health surveys, one by telephone and one by physical examination, the obesity rate from self-reported height and weight was only half of that in the physical examination survey (Schutz and Woringer 2002). Nevertheless changes in prevalence of obesity may be assessed correctly with repeated surveys using standardized methodology (Paccaud et al. 2001). All findings presented so far use cross-sectional data, in which different individuals with the same socio-demographic characteristics are compared at different points in time. Although wellsuited to analyze subpopulation trends over time, the problem with (repeated) cross-sectional data is that gross changes, i.e., variation among individual growth patterns, cannot be analyzed. Accurate changes of overweight and obesity can only be expected from panel studies, where the same individuals are asked several times. Time invariant individual unobserved heterogeneity - like underreported weight - can be controlled for in panel models.

To the best of our knowledge, only one study, a tutorial in biostatistics, has used a similar methodology to study the development of BMI but only in overweight/obese adults (Heo et al. 2003) and only in the U.S. They show that the BMI growth trajectories depend primarily on a combination of age and baseline BMI. Specifically, BMI tends to increase over time in younger overweight people but decrease in older people regardless of degree of obesity.

We compare individual BMI growth patterns from Swiss and U.S. adults and use data from cross-nationally comparable panel data. The goals of this paper are to answer questions like "taking into account variation within individuals, is the individual increase of BMI in certain Swiss age groups slower or faster than in the U.S.?" or "How strong is the cohort 25 effect compared with the time effect?” To answer questions like these requires longitudinal 
data and longitudinal models fitted with these data. To our knowledge this is the first application of a true longitudinal cross-country comparison of individual BMI.

The paper is organized as follows: the first section presents the data used, along with an assessment of the quality of panel data, compared with cross-sectional data. We then motivate

5 and illustrate the longitudinal model for growth, which is fitted with the data. This is followed by a summary of findings and conclusions.

\section{Methods}

Data

While the Swiss Household Panel (SHP) started in 1999 with a sample of 5074 households, the Panel Study of Income Dynamics (PSID) began in 1968 with a sample of 4 802 households. Both panel studies involved samples representative of the residential population. Due to high attrition (Lipps 2007), the SHP included a refreshment sample in 2004, which was also representative of the residential population in Switzerland. The PSID added several new population samples over time. Both the SHP and the PSID used CATI (computer assisted telephone interview) during the waves analyzed here, with an annual surveying period in the SHP, while the PSID administered its survey every other year since 1997. If an "original” sample member moves to a new household in either panel, all new household members become new sample members. Also adolescents who reach the age of 16 become interview eligible. Both the SHP and the PSID data used come from the ex-post harmonized Cross National Equivalent File (CNEF), which guarantees strict comparability (Frick et al. 2007). 
We use only the main samples in both surveys, i.e. the original 1999 sample plus the refreshment sample 2004 from the SHP, and the original sample without the 1997 immigrant sample from the PSID, including new entrants, but excluding the non-white sample. We also exclude individuals aged 17 years or under in their first panel wave. All results are unweighted. The basic weighting variables age and sex are used as explaining variables, which makes cross-sectional weights obsolete. Use of longitudinal weights would exclude all non-original sample members (e.g. all new entrants). Weights are therefore not used in the analyses throughout. Four waves of data from each country contain information on BMI: the 1999, 2001, 2003, and 2005 waves of the PSID, and the 2004, 2005, 2006, and 2007 waves of the SHP. The only small overlap of the two data does not qualify comparability. We test for the influence of the time differences of both surveys. It turns out that once the linear wave effect on BMI is included in the regression model, no single wave or wave*survey dummy is any longer significant. The difference of the times considered in the two surveys therefore does not have an effect on the linear growth patterns.

For the analysis, we drop all outliers, that is, panel respondents

- whose BMI exceeded a value of 60 or who

- changed their BMI by more than 5 in the SHP after one year, or

- changed their BMI by more than 10 in the PSID after two years

The final sample size is 13795 individuals with 41004 reported person-years. Of those in the PSID, $75 \%$ answered in all four waves, $9 \%$ in three, $5 \%$ in two, and $11 \%$ in one of the three waves. In the SHP, $45 \%$ answered in all four waves, $11 \%$ in three, $12 \%$ in two, and $31 \%$ in one of the four waves. Individuals who reported two waves contribute to the change, individuals who reported one wave to the level of the BMI, albeit without leaving a degree of freedom. To keep these sample members however highly reduces bias from attrition. 
In Table 1, we compare some basic socio-demographic characteristics in the SHP and the PSID samples used, from the first wave considered (SHP: 2004, PSID: 1999).

$<$ Table 1 here $>$

Not surprisingly, the U.S. sample is older, has a worse health, but a better education. Effects of these socio-economic factors on BMI will be controlled for in the subsequent analyses.

We use the repeated cross-sectional Swiss Health Survey (SHS) to validate the Swiss Household Panel (SHP). The SHS, aimed at the overall monitoring of health-related risk factors through a telephone survey, is the only survey in Switzerland on general health representative of the residential population. Among the SHS 2002 male adults, 39\% were overweight and $8 \%$ obese; among females, $23 \%$ were overweight and $8 \%$ obese (StatSante 2007). Figure 1 compares these figures with those from the SHP using the 2004 wave.

$<$ Figure 1 here $>$

The values in the SHS and the SHP are very similar. The slightly lower values in the SHP may be due to attrition in the SHP I (1999) sample: attritors are more prevalent among the socially excluded (Lipps 2007) with a supposedly higher BMI. However, the refreshment sample dummy (1999 for SHP I vs. 2004 for SHP II) was not significant for obesity or overweight based on a two-sided t-test. 
$<$ Figure 2 here $>$

The proportions of the overweight persons in the SHS and the SHP by age group are by and large comparable (see Figure 2); however as for obesity, there are some differences. In general, again, the SHP figures probably slightly underestimate BMI in the Swiss population. Note that due to sometimes small sample sizes, the proportions must be interpreted with care.

Data from the U.S. - Behavioral Risk Factor Surveillance System (BRFSS) show that in 1997 and 2002 obesity amounts to 17\% and 22\% in adult females, and overweight to 28\% and 30\%, respectively (Mandal and Chern 2007). The proportions of obese adult men are $17 \%$ and $23 \%$, and $46 \%$ for overweight in both years. Our figures for the PSID data come close to these numbers. The differences might be due to attrition (Zabel 1998; Fitzgerald et al. 1998), and the exclusion of the non-whites. Figure 3 presents these figures.

Table 2 presents some descriptive statistics in the SHP and the PSID, by country and year.

$<$ Table 2 here $>$

Both the level and increase of the BMI over time is much higher in the USA. Because BMI is approximately normally distributed in each wave, we model BMI as a normally distributed variable, without the transformation into the dummies overweight or obese. The reason is that we prefer to model this variable directly, maintaining the full information in the variable in our models. 
The multilevel model for growth

Panel data allow for the analysis of both between-individual and within-individual change 5 of BMI over time. The longitudinal model for growth consists of both change components (Singer and Willett 2003). In the within-individual difference in change (level 1) model, each person's individual growth pattern is characterized. In the between-individual (level 2) model heterogeneity of level and change is analyzed across individuals.

Other than considering the overall mean linear regression line (lower right panel), individual regression lines are weighted according to the goodness of fit of the individual data points to give the overall intercept and growth parameters in a multilevel model for growth 15 (see Figure 4).

The linear level-1 submodel can be written as follows:

$$
b_{i j}=\beta_{0 i}+\beta_{1 i} w a v e+e_{i j} \text { with } e_{i j} \approx N\left(0, \sigma_{\varepsilon}^{2}\right)
$$

20 where $\mathrm{i}$ denotes the individual, $\mathrm{j}$ the wave, $\mathrm{e}_{\mathrm{ij}}$ the error term, and $\sigma_{\varepsilon}^{2}$ is the level- 1 residual variance across the waves. $\beta_{0 i}$ is the intercept of the true change trajectory for individual $\mathrm{i}$, and $\beta_{1 i}$ is the slope of the true change trajectory for individual i. Usual OLS regression assumptions, particularly that the individual's level-1 residuals should not be auto-correlated are typically violated in longitudinal data. 
When a linear growth model at level 1 is used, two level-2 submodels are needed, one for the intercept and one for the slope parameter:

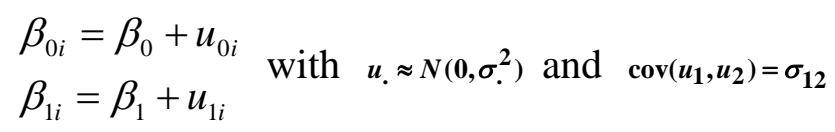

5

The residuals $u_{. i}$ represent those portions of the level-2 outcomes that remain unexplained by the level-2 indicators. A level-2 error covariance $\sigma_{12}$ allows for a nonzero correlation between population intercept and slope.

\section{Results}

Results are listed in Table 3. From the first model we find that almost $8 \%$ $(1.56 /(1.56+18.8))$ of the total variance is due to within-individual variation, with about $92 \%$

15 due to between-individual variation.

$<$ Table 3 here $>$

In the second model, we add the control variables country (U.S. is control group), sex

20 (female), age groups (18-24 years old), education (higher, equal, or lower than high school level; the latter is the control group), working status (not working), and the self rated health (5 categories). The control variables show the expected inverse relationship between SES (Sobal and Stunkard 1989; McLaren 2007; Statsanté 2007) and self-rated health (Ford et al. 2001) on one hand, and obesity on the other. To test if different age groups have a different BMI in the 
two countries, we include the interactions country and age groups. Generally we first include the main effects, before testing the interactions, and then keep only the significant coefficients. We find a different age gradient of the level of the BMI between the two countries: While the "controlled” BMI of the youngest Swiss is about 3.1 points lower than 5 that of the same age group in the U.S., the Swiss elderly (75+ years) have a slightly higher BMI $(-3.07+3.57=.5)$.

In the third model (“Time”), we add both fixed and random effects of Time (Year), and time squared (insignificant). Aim is to calculate the covariance between level and development of BMI, whose positive sign shows that people who have a high initial BMI tend to even increase it over time.

As we are mostly interested in the differences of change in different Swiss and U.S. age cohorts, we center BMI around each individual's mean BMI (“Mid-BMI controlled”). Not surprisingly, the deviance statistic decreases dramatically. By construction, the fixed effect of the intercept (here: mean individual BMI) equals 1. The overall individual BMI growth (.15 by year) is halved in Swiss adults. In the last model, we check if growth differs between different cohorts in both countries, controlled for the "nuisance" of level effects, as in model 3. The yearly growth of the $18-44$ years old amounts to .21 in both countries. There is a smaller increase in the 45-64 years old, and especially the oldest age group, whose BMI actually decreases. In Switzerland, the growth is comparatively smaller at ages 45-55 and especially at ages 25-44 and 55-64. In this respect, the difference in linear growth between Switzerland and the U.S. can be completely attributed to the middle-aged between 25 and 64 . Both the young and old seem to increase their BMI to a similar extent. 


\section{Discussion}

The analyses put forward in this article investigate the problem of increasing body mass index (BMI) prevalent in industrialized societies, by analyzing individual growth patterns in

5 two countries. We examine BMI longitudinally using panel data from two ex-post harmonized household panels from Switzerland and the U.S. We use multilevel models for linear growth.

While there is a strong age gradient of the BMI level between Switzerland and the U.S. with a much higher BMI in U.S. young adults (18-25) and an equal BMI in the oldest age group (75+) we find a positive covariance between initial level and growth coefficient in both countries. With respect to the individual BMI slope, we find a reduced BMI increase from 4564 years on in both countries, which is even slightly negative in the oldest age group (75+). In Switzerland, the BMI growth is smaller in those aged 25-64 years. Extrapolating these findings into the (near) future, the discrepancy of the BMI between the U.S and Switzerland will continue to increase: today’s older cohorts, whose BMI is the more similar the older the cohort is, will be replaced by cohorts with an increasing larger BMI discrepancy.

The limitations of the study are threefold: first, data comprise only four waves in two countries that allow for short-term considerations only. Secondly, both surveys suffer from initial non-response and panel attrition that are usually both correlated with low socioeconomic status and supposedly higher BMI. Studies show that bias due to initial nonresponse is stronger than bias from attrition (Pyy-Martikainen and Rendtel 2008). Analyses that focus on dynamic changes are therefore concerned to a smaller degree. Thirdly, the height and weight data used are self-reported in both surveys. Because they use a similar design and are ex-post harmonized, the reported height and weight are affected in the same way. Also, effects on dynamic aspects are minor. We believe that these issues do not limit our results. 
While Health Promotion Switzerland, a foundation financed by the Swiss cantons and insurance companies, has launched a program to respond to the obesity epidemic in 2005, the U.S. have launched many programs to combat overweight and obesity. Most are still fairly recent, and their effectiveness is not well known. According to this study, it appears that the numerous prevention programs have not succeeded in overcoming the epidemic of overweight and obesity in Switzerland and particularly the U.S.

\section{References}

10

Eichholzer M, Camenzind E (2003) Übergewicht, Adipositas und Untergewicht in der Schweiz: Resultate der Nutri-Trend-Studie 2000. Schweiz Rundsch Med Prax 92 (18):847-858

Fitzgerald J, Gottschalk P, Moffitt R (1998) An Analysis of Sample Attrition in Panel Data:

The Michigan Panel Study of Income Dynamics. J Hum Resour 33 (2), Special Issue: Attrition in Longitudinal Surveys (Spring, 1998):251-299

Flegal KM, Carroll MD, Ogden CL, Johnson CL (2002) Prevalence and trends in obesity among U.S. adults, 1999-2000. JAMA 288:1723-1727

Ford E, Moriarty DG, Zack MM, Mokdad AH, Chapman DP (2001) Self-Reported Body Mass Index and Health-Related Quality of Life: Findings from the Behavioral Risk Factor Surveillance System. Obes Res 9:21-31 
Frick J, Jenkins S, Lillard D, Lipps O, Wooden M (2007) The Cross-National Equivalent File (CNEF) and its Member Country Household Panel Studies. J Appl Soc Sci Studies (Schmollers Jahrbuch) 127 (4):627-654

5 Galobardes B, Costanza MC, Bernstein MS, Delhumeau C, Morabia A (2003) Trends in risk factors for the major lifestyle-related diseases in Geneva, Switzerland, 1993-2000. Ann Epidemiol 13 (7):537-540

Groscurth A, Vetter W, Suter PM (2003) Werden die Schweizer schwerer? Schweiz Rundsch Med Prax 92 (51-52):2191-2200

Heo M, Faith M, Mott J, Gorman B, Redden D, Allison D (2003) Hierarchical linear models for the development of growth curves: an example with body mass index in overweight/obese adults. Stat in Med 22 (11):1911-1942

Kuczmarski RJ, Carrol MD, Flegal KM, Troiano RP (1997) Varying body mass index cutoff points to describe overweight prevalence among U.S. adults NHANES III (1988-1994). Obes Res 5:542-548

Mandal B, Chern WS (2007) A Multilevel Approach to Model Obesity and Overweight in the United States. Department of Agricultural, Environmental \& Development Economics, The Ohio State University, Columbus 
McLaren L (2007) Socioeconomic status and obesity. Epidemiol Rev 29:29-48

Ogden CL, Carroll MD, Curtin LR, McDowell MA, Tabak CJ, Flegal KM (2006) Prevalence of overweight and obesity in the United States, 1999-2004. JAMA 295:1549-1555

5

Paccaud F, Wietlisbach V, Rickenbach M (2001) Body mass index: comparing mean values and prevalence rates from telephone and examination surveys. Rev d'Epidémiol et de Santé Publique 49 (1):33-40

Pyy-Martikainen M, Rendtel U (2008) Assessing the impact of initial nonresponse and attrition in the analysis of unemployment duration with panel surveys. AStA Adv in Stat Analysis 92 (3):297-318

Schutz Y, Woringer V (2002) Obesity in Switzerland: a critical assessment of prevalence in children and adults. Int J Obes \& Related Metabolic Disorders: J Int Assoc for the Study of Obes 26 (Suppl.2):3-11

Singer JD, Willett JB (2003) Applied longitudinal Analysis - Modelling Change and Event Occurrence. Oxford University Press, New York

Sobal J, Stunkard AJ (1989) Socioeconomic status and obesity: a review of the literature. Psychol bull 105 (2):260-275 
StatSanté (2007) Übergewicht bei Erwachsenen in der Schweiz: Aspekte einer multifaktoriellen Problematik. Ergebnisse der Schweizerischen Gesundheitsbefragung 2002. Swiss Federal Statistical Office 3/2007, Neuchâtel

5 Zabel, JE (1998) An Analysis of Attrition in the Panel Study of Income Dynamics and the Survey of Income an Program Participation with an Application to a Model of Labor Market Participation. J Hum Resour 33 (2), Special Issue: Attrition in Longitudinal Surveys, (Spring, 1998):479-506 


\begin{tabular}{|c|c|c|}
\hline & $\begin{array}{l}\text { PSID } \\
\text { (USA) }\end{array}$ & $\begin{array}{c}\text { SHP } \\
\text { (Switzerland) }\end{array}$ \\
\hline Year & 1999 & 2004 \\
\hline $\mathrm{N}$ [individuals] & 4315 & 7294 \\
\hline Male [\%] & 47 & 44 \\
\hline Age: 18-24 [\%] & 5 & 9 \\
\hline Age: $25-34$ [\%] & 19 & 14 \\
\hline Age: 35-44 [\%] & 22 & 24 \\
\hline Age: 45-54 [\%] & 20 & 21 \\
\hline Age: 55-64 [\%] & 12 & 16 \\
\hline Age: $65-74$ [\%] & 12 & 10 \\
\hline Age: $75+[\%]$ & 10 & 6 \\
\hline Working [\%] & 65 & 72 \\
\hline Less than High School [\%] & 18 & 16 \\
\hline High School [\%] & 36 & 53 \\
\hline More than High School [\%] & 46 & 30 \\
\hline Self rated Health: very bad [\%] & 4 & 0 \\
\hline Self rated Health: bad [\%] & 10 & 2 \\
\hline Self rated Health: average [\%] & 27 & 13 \\
\hline Self rated Health: good [\%] & 34 & 60 \\
\hline Self rated Health: very good [\%] & 24 & 25 \\
\hline
\end{tabular}

Table 1: Socio-Demography of the PSID and the SHP analytic sample, data from the first year observed 


\begin{tabular}{|c|c|c|c|c|c|c|c|c|}
\hline & \multicolumn{4}{|c|}{ PSID (USA) } & \multicolumn{4}{|c|}{ SHP (Switzerland) } \\
\hline Year & 1999 & 2001 & 2003 & 2005 & 2004 & 2005 & 2006 & 2007 \\
\hline $\mathrm{N}$ & 4315 & 4125 & 4014 & 4226 & 7294 & 5819 & 5532 & 5679 \\
\hline Mean BMI & 25.8 & 26.1 & 26.6 & 26.9 & 24.1 & 24.1 & 24.3 & 24.3 \\
\hline Std. Error & .072 & .077 & .081 & .085 & .045 & .050 & .052 & .051 \\
\hline
\end{tabular}

Table 2: Descriptive statistics of BMI in the four waves analyzed in the Panel Study of Income Dynamic (PSID) and the Swiss Household Panel (SHP) 
Switzerland

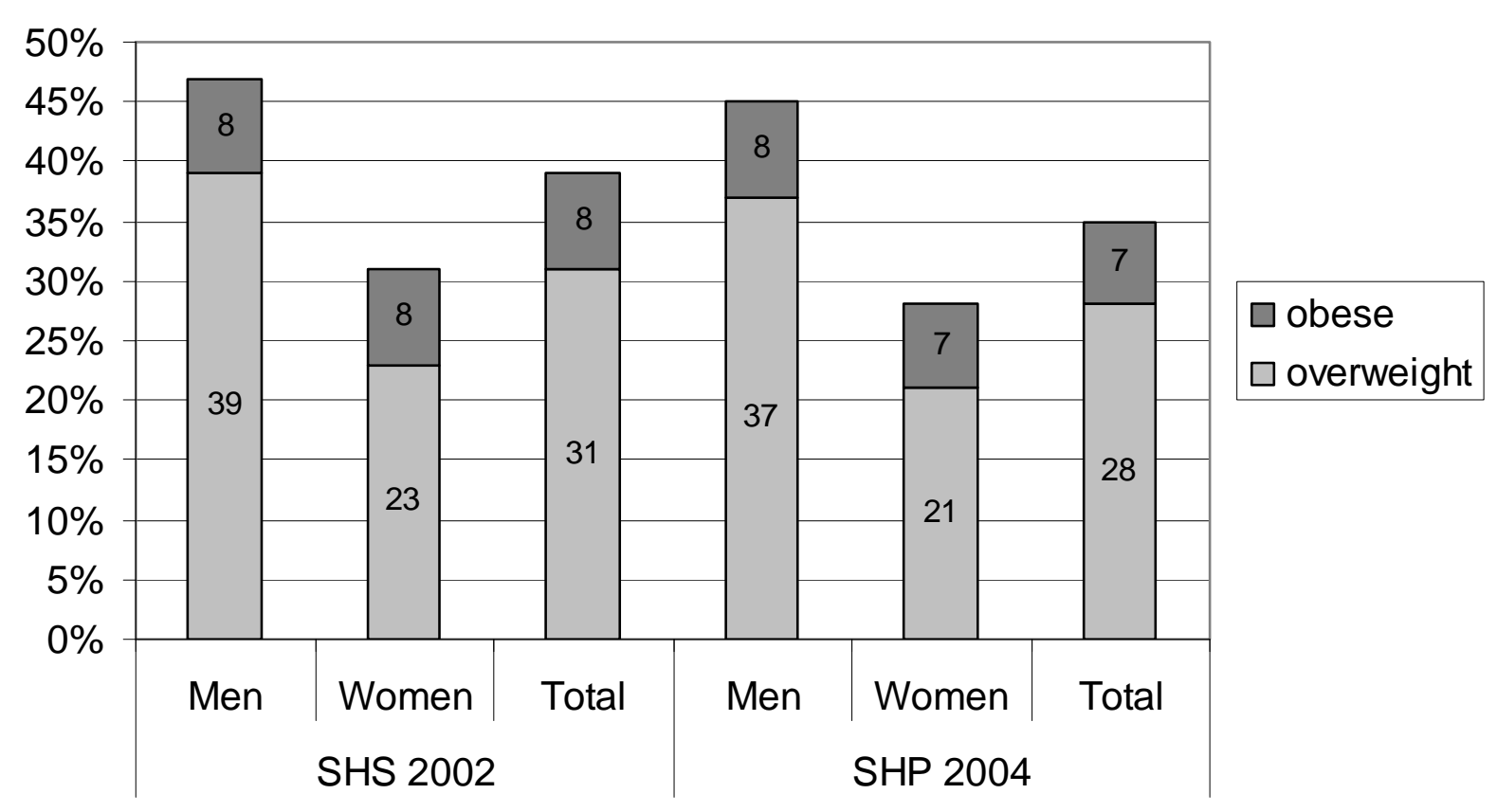

Figure 1: Prevalence (\%) of overweight and obesity in Switzerland, for adults 18 and older. Data: Swiss

5 Health Survey (SHS), Swiss Household Panel (SHP) 


\section{Women}

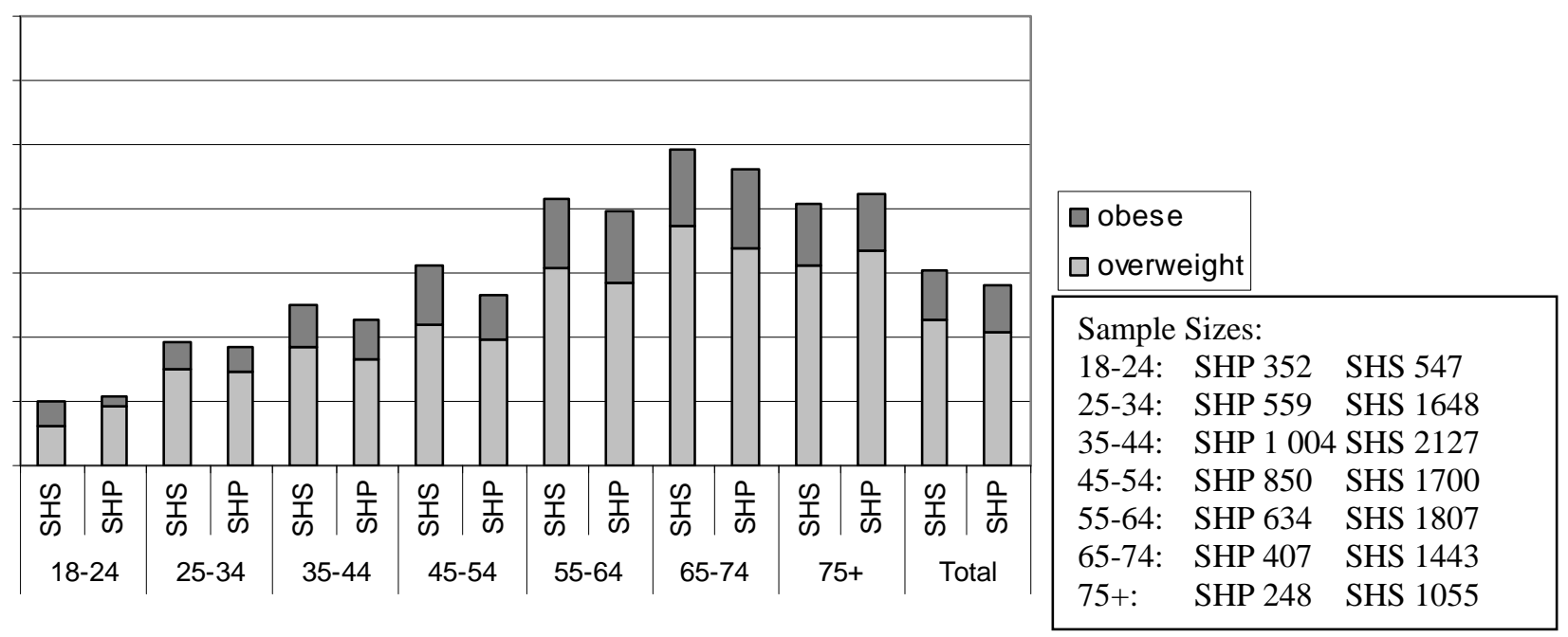

\section{Men}

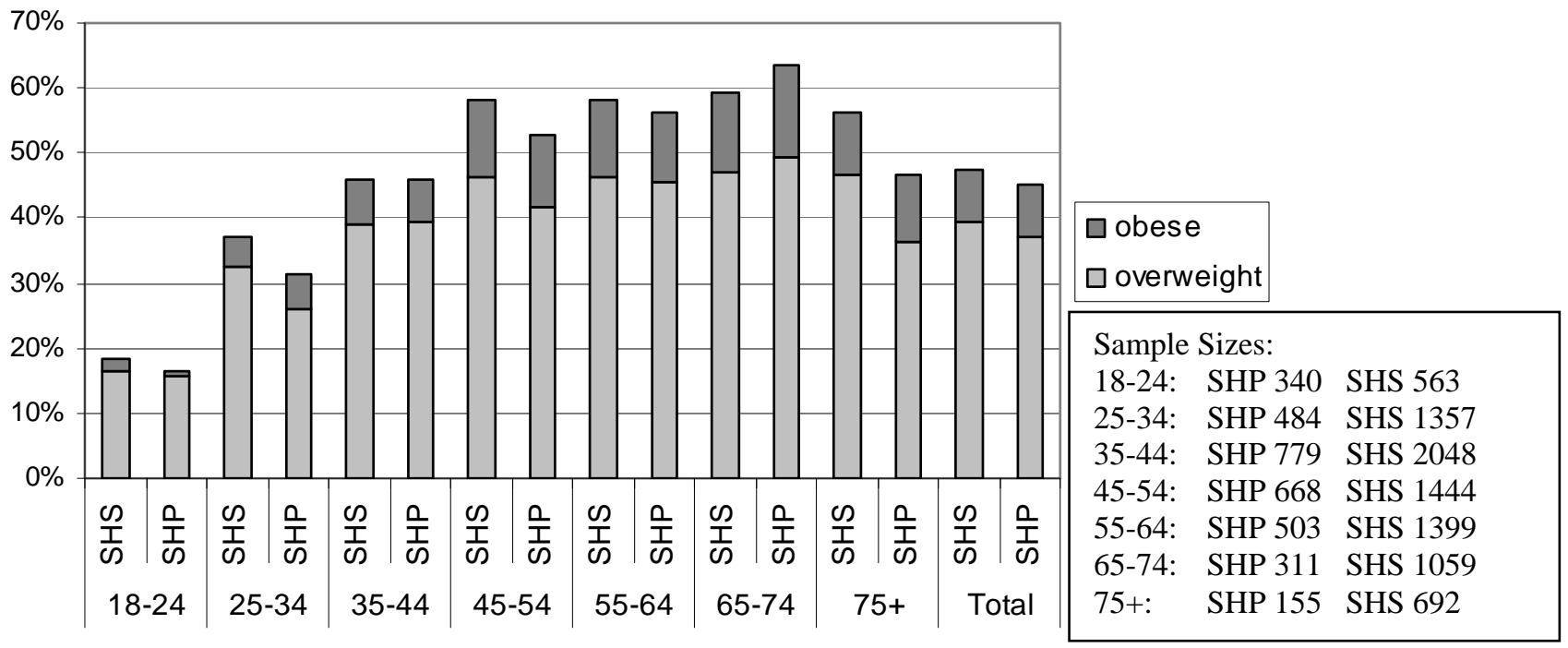

Figure 2: Prevalence (\%) of overweight and obesity of men and women, and sample size by age groups in

Switzerland. Data: Swiss Health Survey (SHS, 2002) and Swiss Household Panel (SHP, 2004) 
USA

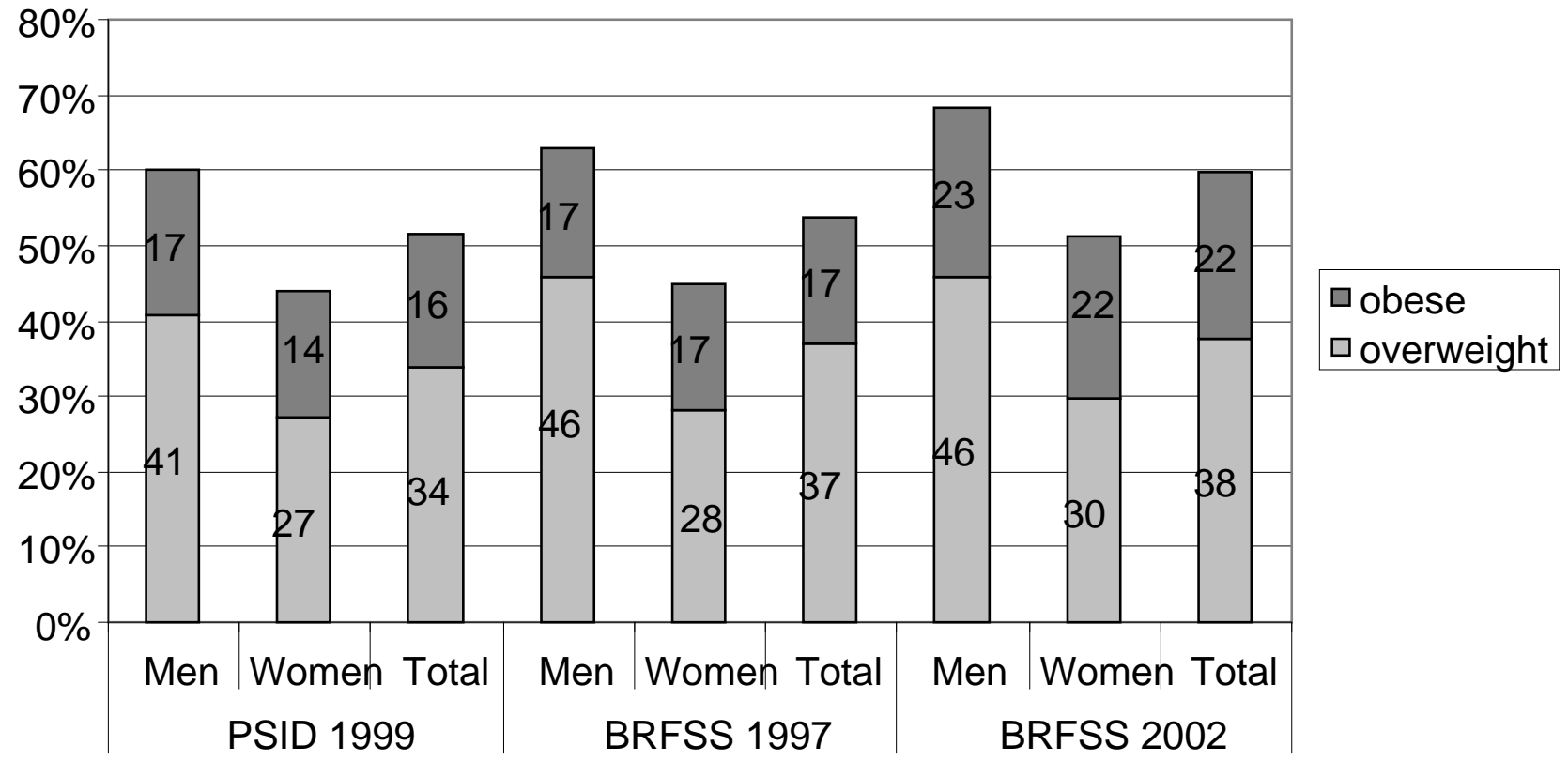

Figure 3: Prevalence (\%) of overweight and obesity of men and women by age groups in the USA. Data:

Panel Study of Income Dynamics (PSID, 1999), Behavioral Risk Factor Surveillance System (BRFSS,

5 1997, 2002) 

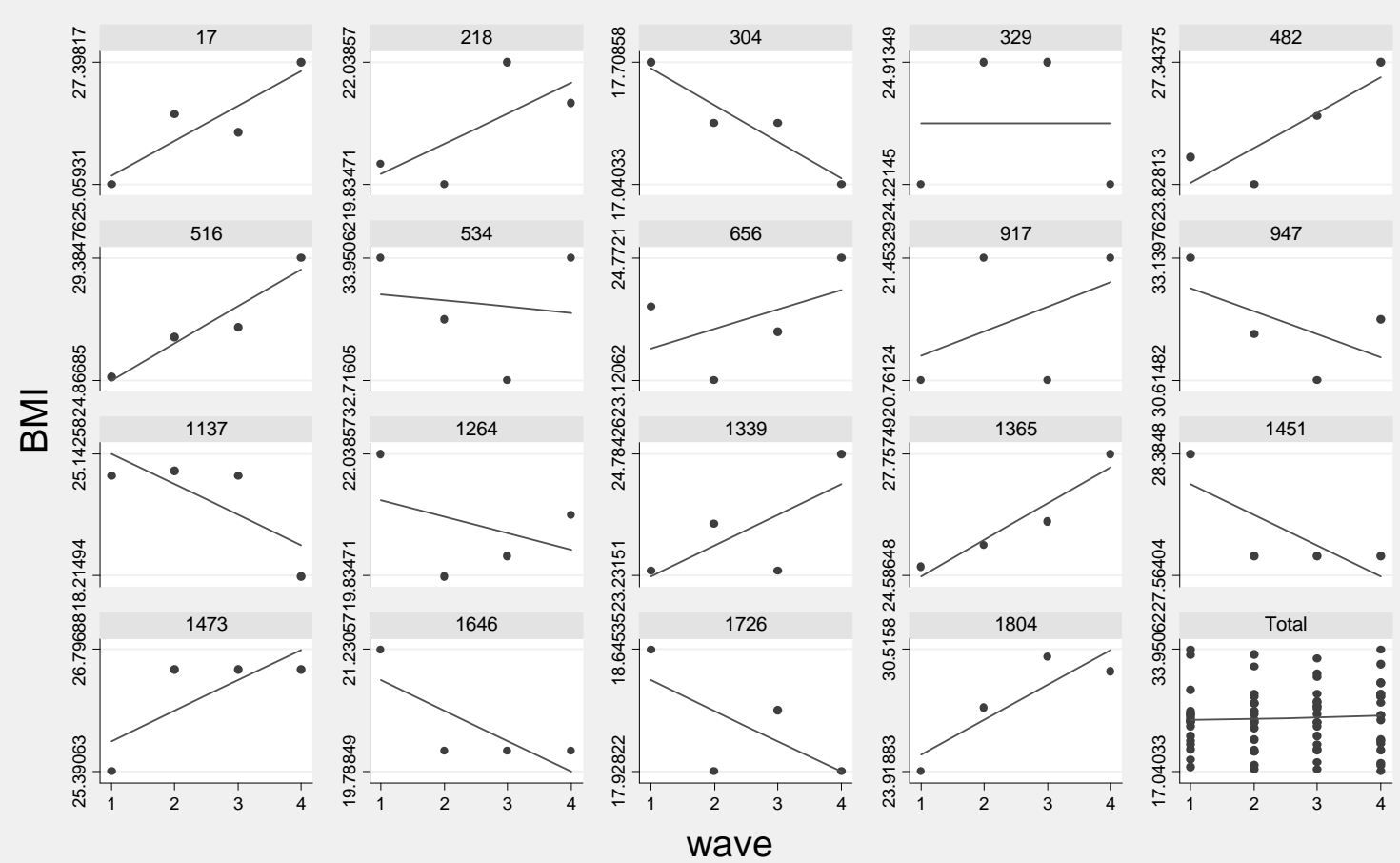

- bmi Fitted values

Graphs by group(pers)

Figure 4: Individual BMI with OLS regression lines of randomly selected individuals in the Swiss Household Panel (SHP, 2004-2007) 


\begin{tabular}{|c|c|c|c|c|c|}
\hline Model & $\begin{array}{l}\text { 1. Variance } \\
\text { Components }\end{array}$ & $\begin{array}{l}\text { 2. Soc.demo. } \\
\text { controlled }\end{array}$ & 3. Time & $\begin{array}{l}\text { 4. Mid-BMI } \\
\text { controlled }\end{array}$ & $\begin{array}{l}\text { 5. Age Time- } \\
\text { Country }\end{array}$ \\
\hline Intercept & 24. & 25.33 & 24.11 & 1 (by constr) & 1 (by constr) \\
\hline Male & & 1.63 & 1.68 & & \\
\hline More than High School & & -.16 & -.34 & & \\
\hline Working & & -.15 & -.12 & & \\
\hline Health $(1 \ldots 5=$ very good $)$ & & -.18 & -.09 & & \\
\hline Age: 25-34 (Ref: 18-24) & & 1.07 & 1.13 & & * Time: - \\
\hline Age: $35-44$ & & 1.41 & 1.89 & & * Time: - \\
\hline Age: $45-54$ & & 1.81 & 2.37 & & * Time: -.06 \\
\hline Age: 55-64 & & 1.62 & 2.18 & & * Time: -.07 \\
\hline Age: $65-74$ & & 1.08 & 1.92 & & * Time: - \\
\hline Age: $75+$ & & -.84 & & & * Time: -.29 \\
\hline Swiss & & -3.07 & -2.36 & & \\
\hline Swiss * Age: $25-34$ & & - & - & & * Time: -.10 \\
\hline Swiss * Age: $35-44$ & & .54 & - & & * Time: -.11 \\
\hline Swiss * Age: 45-54 & & .60 & - & & * Time: -.06 \\
\hline Swiss * Age: 55-64 & & 1.42 & .90 & & * Time: -.11 \\
\hline Swiss * Age: 65-74 & & 2.36 & 1.57 & & * Time: - \\
\hline Swiss * Age: $75+$ & & 3.57 & 2.84 & & * Time: - \\
\hline & & & & & \\
\hline
\end{tabular}




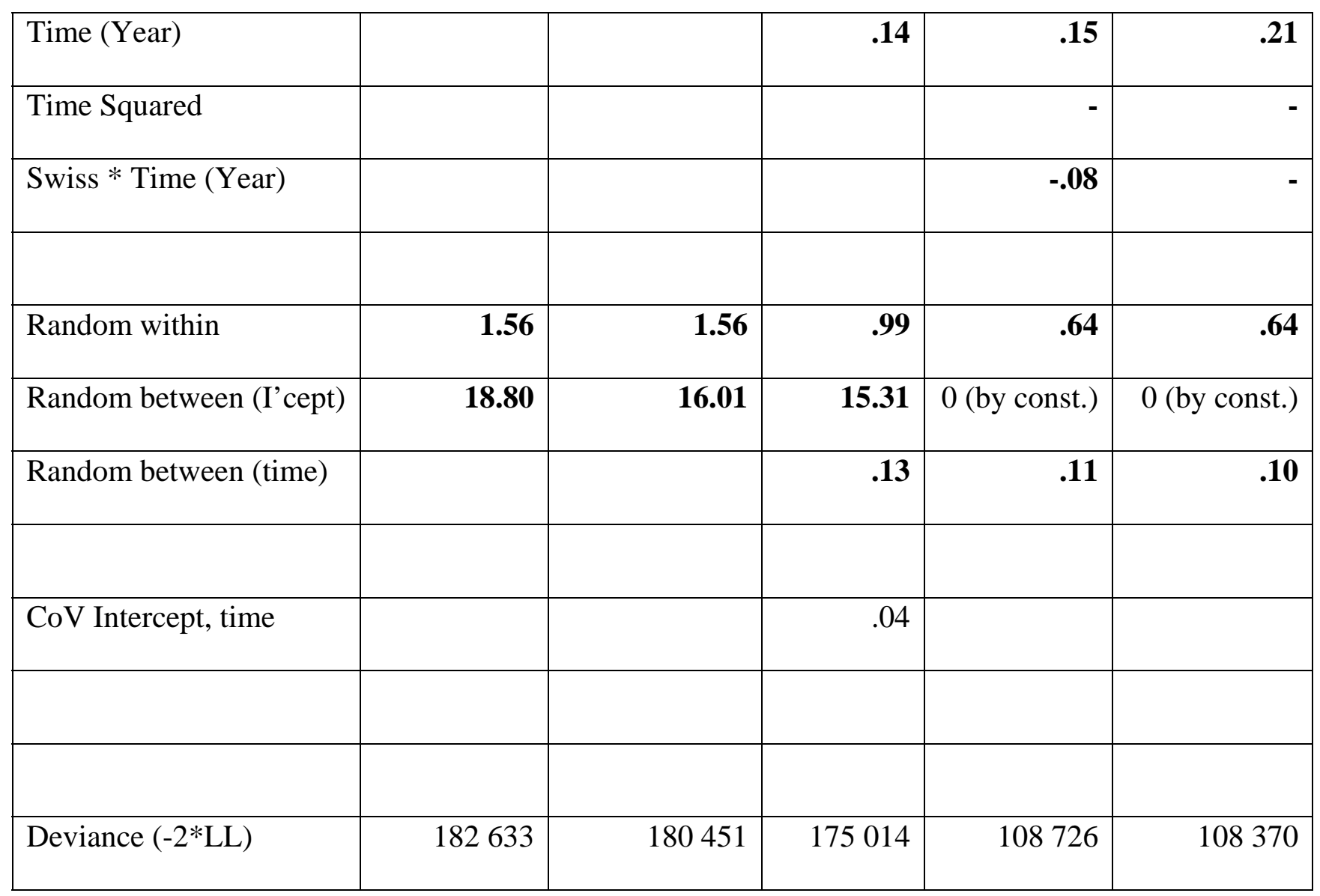

Table 3: Individual Model for BMI Growth Results, Data: SHP (2004-2007) and PSID (1999-2005), N=41 004 person-years

All listed Coefficients "significant”: at least twice their standard error. Bold: at least 10x their 5 standard error, “-“: not significant, dropped, “ “: not included in model. 